\title{
Midlife Healthy-Diet Index and Late-Life Dementia and Alzheimer's Disease
}

\author{
Marjo H. Eskelinen ${ }^{a}$ Tiia Ngandu ${ }^{a, b}$ Jaakko Tuomilehto ${ }^{\text {b-d }}$ \\ Hilkka Soininen $^{a}$ e Miia Kivipelto ${ }^{a}, f$ \\ ${ }^{a}$ Department of Neurology, University of Eastern Finland, Kuopio, ${ }^{b}$ Department of Health \\ Promotion and Chronic Disease Prevention, National Institute for Health and Welfare, \\ 'Department of Public Health, University of Helsinki, Helsinki, d South Ostrobothnia Central \\ Hospital, Seinäjoki, and ' Department of Neurology, Kuopio University Hospital, \\ Kuopio, Finland; ${ }^{f}$ Aging Research Center, Karolinska Institutet, Stockholm, Sweden
}

\section{Key Words}

Alzheimer's disease $\cdot$ Cohort studies $\cdot$ Dementia $\cdot$ Diet $\cdot$ Population-based studies • Risk factors

\begin{abstract}
Aim: To study long-term effects of dietary patterns on dementia and Alzheimer's disease (AD). Methods: Of 525 subjects randomly selected from population-based cohorts surveyed at midlife, a total of $385(73 \%)$ subjects were re-examined 14 years later in the CAIDE study. A healthy-diet index (range 0-17) was constructed including both healthy and unhealthy dietary components. Results: Persons with a healthy diet (healthy-diet index $>8$ points) had a decreased risk of dementia (OR $0.12,95 \% \mathrm{Cl} 0.02-0.85)$ and AD (OR $0.08,95 \% \mathrm{Cl} 0.01-0.89)$ compared with persons with an unhealthy diet (0-8 points), adjusting for several possible confounders. Conclusions: Healthy diet at midlife is associated with a decreased risk of dementia/ $A D$ in late life. These findings highlight the importance of dietary patterns and may make more effective measures for dementia/AD prevention or postponement possible.
\end{abstract}




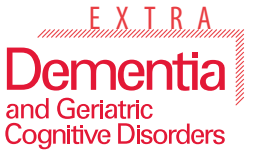

\begin{tabular}{l|l}
\hline Dement Geriatr Cogn Disord Extra 2011;1:103-112 \\
\hline DOI: 10.1159/000327518 & $\begin{array}{l}\text { @ 2011 S. Karger AG, Basel } \\
\text { www.karger.com/dee }\end{array}$ \\
\hline Published online: April 27, 2011 &
\end{tabular}

Eskelinen et al.: Midlife Healthy-Diet Index and Dementia/AD

\section{Introduction}

Various single dietary components have been linked with cognitive impairment and dementia/Alzheimer's disease (AD). For example, it has been reported that a diet rich in saturated fatty acids (SFAs) and cholesterol may increase the risk of dementia/AD, whereas polyunsaturated fatty acids (PUFAs) and fish may be protective $[1,2]$. Also, higher dietary intake of vitamin $\mathrm{E}$, vitamin $\mathrm{C}$, and flavonoids, and higher levels of vitamin $\mathrm{B}_{12}$ and folate have been associated with a reduced risk of cognitive impairment and dementia/AD, although these findings are not uniform across studies [2]. Furthermore, moderate coffee drinking [3] and alcohol consumption [4] have been suggested to decrease the risk of cognitive impairment and dementia/AD, but these findings are also not unequivocal [4].

So far, the main focus of studies on diet and dementia has been on single dietary components. However, single nutrients are not consumed in isolation but as a part of a dietary pattern. Examining the role of single nutrients/food items is complicated because they are strongly correlated. Also, the many possible interactions between nutrients are difficult to estimate. Therefore, examining dietary patterns rather than single nutrients might be more useful in understanding the role of diet in chronic diseases. A healthy diet has been linked, among other factors, with a reduced risk of mortality from cardiovascular diseases and cancers, as well as lower incidences of Parkinson's disease and diabetes [5]. Only three previous longitudinal studies have investigated the relationship between a healthy diet (including several dietary components) and dementia/AD. A recent report from the Washington HeightsInwood Columbia Aging Project (WHICAP) among elderly persons found that a dietary pattern rich in several single nutrients earlier identified as reducing the risk of AD was associated with a reduced risk of AD during a follow-up of 4 years [6]. An earlier report from the same project found that higher adherence to the Mediterranean diet was associated with a decreased risk of $\mathrm{AD}$ development [7] as well as with lower mortality in $\mathrm{AD}$ [8]. In the Three-City (3C) study among elderly persons, the Mediterranean diet was associated with a slower decline in the Mini-Mental State Examination (MMSE), but not with dementia/AD risk over a 5-year period [9]. All these previous studies were conducted among elderly persons, and follow-up times were relatively short.

Today, no studies exist on whether a healthy diet as early as in midlife has an effect on the risk of developing dementia later on. The aim of our study was to investigate the associations of a midlife healthy diet with the development of dementia and AD later in life in a population-based cohort of people living in Eastern Finland. The healthy-diet index was constructed using information on both beneficial and detrimental components of individuals' midlife diet.

\section{Participants and Methods}

\section{Study Population}

The participants of the Cardiovascular risk factors, Aging and Dementia (CAIDE) study were randomly selected from survivors of population-based random samples firstly studied within the North Karelia Project and the FINMONICA study in 1972, 1977, 1982, or 1987 (baseline, midlife visit) [10]. A random sample of 2,000 survivors aged 65-79 years at the end of 1997 and living in the study area in Eastern Finland (in Joensuu or Kuopio) were invited to the re-examination in 1998 [11]. Altogether 1,409 (70.5\%) individuals completed the follow-up examination (late-life visit). For the current study, we used the sub-samples, who were first enrolled in 1982 or 1987, because of the more extensive dietary information available. Of these 525 people, 385 (73.3\%) participated. These 239 women (62.1\%) and 146 men (37.9\%) 
had a mean (SD) age of 56.7 (4.0) years at the time of their midlife examination, and 70.6 (3.7) years at the time of their late-life examination in 1998. All participants gave written informed consent in 1998, and the local Ethical Committee of Kuopio University and Kuopio University Hospital approved the study.

\section{Measurements}

The survey methods used during the baseline visit were carefully standardized and complied with international recommendations [12]. In brief, the survey included an exhaustive self-administered questionnaire on health behavior (including dietary habits), health status and medical history. Systolic (SBP) and diastolic blood pressure (DBP), height and weight were measured, body mass index (BMI) was calculated, and a venous blood sample was taken to determine serum cholesterol. During the follow-up examination in 1998, the survey methods followed those utilized in the previous surveys in all aspects. Additionally, the apolipoprotein E (APOE) genotype of participants was determined with a method described by Tsukamoto et al. [13], and the cognitive status was assessed [11].

\section{Assessment of Cognitive Status}

Global cognitive function was assessed first with the MMSE [14]. For the diagnosis of dementia, a three-step protocol (screening, clinical, and differential diagnostic phase) was used; individuals scoring $\leq 24$ on the MMSE were addressed for further diagnostic examination. The diagnosis of dementia was based on DSM-IV criteria, and probable and possible $\mathrm{AD}$ was diagnosed according to the NINCDS-ADRDA criteria [15]. Of the 1982 and 1987 sub-population, a total of 13 persons met the diagnosis of dementia, out of whom 11 had AD. All patients with AD showed generalized or medial temporal atrophy, and none showed appreciable vascular pathology on magnetic resonance scans. Isolated minor lacunae or periventricular white matter signal changes were not considered as exclusion criteria for AD. All patients with AD scored $\leq 4$ on the Hachinski ischemia scale [16]. When diagnoses derived from the patient records of the non-participants in the follow-up examination were taken into account, the number of demented persons increased to 29 .

\section{Dietary Assessment and Formation of a Healthy-Diet Index}

Dietary habits were inquired with a survey questionnaire consisting of approximately 20 mostly qualitative or frequency-based multiple choice questions, but some questions, e.g. the consumption of coffee and eggs, were assessed quantitatively at the midlife examination. The usual number of bread slices consumed per day, and the type and amount of spread used was inquired during the examination.

For calculating the healthy-diet index, we modified the method that Trichopoulou et al. [17] used for the construction of the Mediterranean diet score. A value of 0 or 1 was assigned to each of the 18 food groups, using mainly sex-specific medians as cutoffs. For beneficial components [vegetables and roots, berries and fruits, bread, fish, coffee drinking, monounsaturated fatty acids (MUFAs) and PUFAs from milk products and spreads], persons whose consumption was below the median were assigned a value of 0 and persons whose consumption was at or above the median were assigned a value of 1 . For components presumed to be unhealthy (sausage foods, eggs, candies, sweet soft drinks, sugar lumps in coffee, salty fish, and SFAs from milk products and spreads), points were given vice versa (below the me$\operatorname{dian}=1$, at or above the median $=0$ ). The consumption of salty fish was available for the 1982 sample only, and the consumption of fish for the 1987 sample only. In the final index, the information that was available on these two variables was used. For alcohol drinking, a value of 1 was assigned to persons with moderate alcohol consumption and a value of 0 to persons not consuming alcohol or consuming abundantly (moderate and abundant were de- 
fined with sex-specific median values among drinkers). For the use of salt on the dining table, a value of 1 was given to persons who were not adding salt to the meals and a value of 0 to the other categories (i.e. adding salt when the food is not salty enough or almost always before tasting). Finally, we also included fats used for cooking and baking in the household into our healthy-diet index: using vegetable oil or margarine was assigned a value of 1 and butter or a butter-oil mixture a value of 0 . There were some missing values for some of the food groups ( $0-19$ persons with missing values apart from the variable 'fat used in baking', where there were 51 missing values). Those with missing values were given 0.5 points for the respective food group. After adding up the points of every food category, we received the total healthy-diet index that could range theoretically from 0 (minimal adherence to healthy diet) to 17 (maximal adherence). The healthy-diet index was dichotomized based on median values: $0-8$ points (low adherence to healthy diet) and $>8$ points (high adherence to healthy diet).

\section{Statistical Analyses}

All statistical analyses were conducted using PASW statistics, version 17 (SPSS Inc., Chicago, Ill., USA). To assess differences between persons according to their dietary habits, independent samples $t$ tests and $\chi^{2}$ tests were run. Logistic regression models were used to analyze the independent effect of a healthy diet on the risk of dementia and AD so that the group with low adherence to a healthy diet served as the reference group. Possible confounders were added in blocks in the analyses. Odds ratios (OR) with $95 \%$ confidence intervals (CI) were calculated. Model 1 was adjusted for age, sex, education, follow-up time, community of residence, and APOE $\varepsilon 4$ carrier status. Model 2 was adjusted additionally for cardiovascular risk factors including midlife SBP, serum total cholesterol, BMI, and the presence of late-life myocardial infarction/stroke/diabetes mellitus. Model 3 was adjusted additionally for midlife leisure-time physical activity and smoking. For MMSE, analysis of covariance (ANCOVA) was applied with similar adjustments as for dementia and AD. Bonferroni adjustments were used for multiple comparisons. The level of significance was $\mathrm{p}<0.05$. For the non-participants, logistic regression analyses were done to the appropriate extent (model 1 was adjusted for age, sex, education, and community of residence; model 2 was adjusted additionally for midlife SBP, serum total cholesterol and BMI, and model 3 was adjusted additionally for midlife leisure-time physical activity and smoking).

\section{Results}

The composition of the CAIDE midlife healthy-diet index with the sex-specific cutoff values is given in table 1 . In our population, the scores ranged from 2 to 14.5 , with no subjects having the absolute lowest or highest possible scores.

At midlife, persons with a high adherence to a healthy diet were more educated compared with persons with a low adherence to a healthy diet. DBP and BMI were higher among those with a low adherence to a healthy diet, and also the proportion of persons with a sedentary lifestyle was higher in this group. Persons who had the healthiest diet at midlife had the lowest occurrence of dementia and AD late in life (table 2).

The non-participants of the follow-up examination were older, less educated, and had higher SBP, DBP, and serum total cholesterol at midlife than the participants. They were also more often demented (diagnoses from patient records) than the participants. Altogether $59.0 \%$ of the non-participants belonged to the group with a low adherence to a healthy diet compared to $53.7 \%$ of the participants; however, the difference was not statistically significant $(\mathrm{p}=0.29)$. 


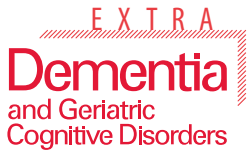

\begin{tabular}{l|l}
\hline \multicolumn{2}{l}{ Dement Geriatr Cogn Disord Extra 2011;1:103-112 } \\
\hline $\begin{array}{l}\text { DOI: } 10.1159 / 000327518 \\
\text { Published online: April 27, } 2011\end{array}$ & $\begin{array}{l}\text { @ 2011 S. Karger AG, Basel } \\
\text { www.karger.com/dee }\end{array}$ \\
\hline
\end{tabular}

Table 1. Formation of the CAIDE midlife healthy-diet index

\begin{tabular}{|c|c|c|}
\hline \multirow[t]{2}{*}{ Food consumption } & \multicolumn{2}{|l|}{ Points ${ }^{\mathrm{a}}$} \\
\hline & men & women \\
\hline Beneficial components & 1 point, if ... & 1 point, if... \\
\hline Vegetables and roots & $\geq 1$ time per week & $\geq 3$ times per week \\
\hline Berries and fruits & $\geq 1$ time per week & $\geq 3$ times per week \\
\hline Bread & $\geq 5$ slices per day & $\geq 3$ slices per day \\
\hline Fish (in subsample only) ${ }^{b}$ & $\geq 1$ time a week & $\geq 1$ time per week \\
\hline Coffee & $\geq 4$ cups a day & $\geq 3$ cups per day \\
\hline MUFA from milk products and spreads ${ }^{c}$ & $\geq 11.2$ g per day & $\geq 6.13$ g per day \\
\hline PUFA from milk products and spreads ${ }^{c}$ & $\geq 2.06$ g per day & $\geq 1.04$ g per day \\
\hline \multicolumn{3}{|l|}{ Detrimental/unhealthy components } \\
\hline Sausage foods & $<$ twice per month & $<$ once per month \\
\hline Eggs (boiled, fried) & $<2$ per week & $<2$ per week \\
\hline Candies & never & never \\
\hline Sweet soft drinks & never & never \\
\hline Sugar lumps in tea and coffee & $<6$ lumps per day & $<2$ lumps per day \\
\hline Salty fish (in subsample only) & $<$ once per month & $<$ once per month \\
\hline SFA from milk products and spreads ${ }^{c}$ & $<19.5$ g per day & $<10.2$ g per day \\
\hline Alcohol drinking ${ }^{\mathrm{d}}$ & $\begin{array}{l}\text { moderate drinking } \\
\quad(1-60 \text { g per week })\end{array}$ & $\begin{array}{l}\text { moderate drinking } \\
\quad(1-24 \text { g per week })\end{array}$ \\
\hline Use of salt on the dining table & not adding salt to meals & not adding salt to meals \\
\hline Type of fats used for cooking & vegetable oil or margarine & vegetable oil or margarine \\
\hline Type of fats used for baking & vegetable oil or margarine & vegetable oil or margarine \\
\hline
\end{tabular}

Total score indicating adherence to healthy diet: $0-8$ points $=$ low adherence; $>8$ points $=$ high adherence.

${ }^{a}$ One point for each variable was given if a person had a consumption level at or above the sex-specific median level for the beneficial component, and below the sex-specific median for detrimental components. For variables where medians were not used, a favorable consumption pattern was given 1 point. For alcohol drinking, moderate drinking was defined as drinking below the sex-specific median among drinkers. Both non-drinkers and heavy drinkers had 0 points.

${ }^{b}$ In the calculation of the diet index, information on salty fish consumption was available for subjects included in 1982 and fish consumption for subjects included in 1987. Therefore, there were 17 items available for each subject.

${ }^{\mathrm{c}}$ For example, $5 \mathrm{~g}$ of spread (margarine containing 60\% fat) contains $1.2 \mathrm{~g}$ MUFAs, $0.9 \mathrm{~g}$ PUFAs, and $0.7 \mathrm{~g}$ SFAs (values may vary depending on product), and 1 glass $(2 \mathrm{dl})$ of semi-skimmed milk ( $1.5 \%$ fat $)$ contains $0.7 \mathrm{~g}$ MUFAs, $0.1 \mathrm{~g}$ PUFAs, and $2.1 \mathrm{~g}$ SFAs.

${ }^{\mathrm{d}}$ One glass of wine or 1 shot of liquor contains on average $12 \mathrm{~g}$ of alcohol, 1 bottle of beer contains $12.5 \mathrm{~g}$ and 1 bottle of long drink contains $14.5 \mathrm{~g}$ of alcohol.

The subjects with a high adherence to a healthy diet performed better on global cognitive function than those with a low adherence to a healthy diet [model 3: mean MMSE (standard error, SE) $26.2(0.2)$ vs. $25.6(0.2)$, respectively, $\mathrm{p}=0.02]$.

Those persons who ate healthiest had an $86-90 \%$ decreased risk of dementia and a 90 $92 \%$ decreased risk of AD compared with persons whose diet was least healthy (table 3). Adjustments for various confounders did not change the results. When we rerun the analyses for dementia also including diagnoses from the patient records for the non-participants in the follow-up, persons in the high-adherence group showed a tendency towards a decreased risk of dementia compared with the group with a low adherence to a healthy diet (model 1: OR 0.5, 95\% CI 0.23-1.27; model 2: OR 0.27, 95\% CI 0.07-1.00; model 3: OR 0.28, 95\% CI $0.07-1.09)$. 


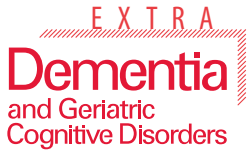

\begin{tabular}{|c|c|}
\hline \multicolumn{2}{|c|}{ Dement Geriatr Cogn Disord Extra 2011;1:103-112 } \\
\hline $\begin{array}{l}\text { DOI: 10.1159/000327518 } \\
\text { Published online: April 27, } 2011\end{array}$ & $\begin{array}{l}\text { (c) } 2011 \text { S. Karger AG, Basel } \\
\text { www.karger.com/dee }\end{array}$ \\
\hline
\end{tabular}

Table 2. Demographic and clinical characteristics by healthy-diet index for the CAIDE participants

\begin{tabular}{|c|c|c|c|c|}
\hline Characteristics & & $\begin{array}{l}\text { Low adherence } \\
\text { ( } 0-8 \text { points }) \\
n=289\end{array}$ & $\begin{array}{l}\text { High adherence } \\
\text { (>8 points) } \\
\mathrm{n}=236\end{array}$ & $\begin{array}{l}\mathrm{p} \\
\text { value }\end{array}$ \\
\hline \multicolumn{5}{|l|}{ Demographics } \\
\hline \multirow[t]{2}{*}{ Age, years } & Midlife & $56.9 \pm 4.1$ & $57.2 \pm 3.9$ & 0.37 \\
\hline & Late life & $71.1 \pm 3.8$ & $71.1 \pm 3.9$ & 0.85 \\
\hline \multirow[t]{2}{*}{ Sex } & Men & 37.4 & 39.4 & 0.63 \\
\hline & Women & 62.6 & 60.6 & \\
\hline Follow-up time, years & & $14.2 \pm 2.4$ & $14.0 \pm 2.5$ & $<0.24$ \\
\hline \multirow[t]{2}{*}{ Community } & Kuopio & 48.4 & 45.8 & 0.54 \\
\hline & Joensuu & 51.6 & 54.2 & \\
\hline Education, years & & $7.7 \pm 3.0$ & $8.8 \pm 3.7$ & 0.00 \\
\hline \multicolumn{5}{|l|}{ Midlife vascular factors } \\
\hline $\mathrm{SBP}, \mathrm{mm} \mathrm{Hg}$ & & $149.4 \pm 22.1$ & $147.4 \pm 19.9$ & 0.28 \\
\hline DBP, mm Hg & & $88.7 \pm 12.0$ & $86.3 \pm 11.0$ & 0.02 \\
\hline Total cholesterol, mmol/l & & $6.7 \pm 1.2$ & $6.6 \pm 1.3$ & 0.30 \\
\hline BMI & & $27.9 \pm 4.6$ & $27.1 \pm 4.0$ & 0.04 \\
\hline \multirow[t]{2}{*}{ Leisure time exercise ${ }^{a}$} & Active & 39.6 & 52.7 & 0.00 \\
\hline & Sedentary & 60.4 & 47.3 & \\
\hline \multirow[t]{3}{*}{ Smoking ${ }^{\mathrm{b}}$} & Current smoker & 18.1 & 18.3 & 0.97 \\
\hline & Former smoker & 21.4 & 20.5 & \\
\hline & Never smoked & 60.5 & 61.1 & \\
\hline \multicolumn{5}{|c|}{ Late-life clinical characteristics } \\
\hline Dementia & & 5.3 & 1.1 & 0.02 \\
\hline $\mathrm{AD}$ & & 4.9 & 0.6 & 0.01 \\
\hline Myocardial infarction & & 13.5 & 14.5 & 0.78 \\
\hline Stroke & & 6.8 & 7.3 & 0.85 \\
\hline Diabetes mellitus & & 7.2 & 6.2 & 0.69 \\
\hline \multirow[t]{2}{*}{ APOE $\varepsilon 4$} & Carriers & 30.6 & 36.2 & 0.25 \\
\hline & Non-carriers & 69.4 & 63.8 & \\
\hline
\end{tabular}

Analysis of variance was used for continuous and $\chi^{2}$ test for categorical variables. The values are means \pm SD or percentages unless otherwise stated.

a Physically active at leisure time indicates exercise at least twice a week, while physically sedentary/ inactive at leisure time indicates exercise less than twice a week.

${ }^{\mathrm{b}}$ Current smoker $=$ Has smoked within a year; former smoker $=$ has smoked $>1$ year ago; never smoked $=$ has never smoked.

\section{Discussion}

Our findings indicate that adherence to a healthy diet already at midlife is associated with a decreased risk of dementia and AD later in life. Although a healthy diet is an important determinant for the level of several risk factors for dementia, e.g. blood pressure, serum cholesterol, diabetes, and obesity, the effect of a healthy diet remained highly significant even after adjustments for several potential confounding or mediating factors, suggesting an independent effect of the healthy diet. There is only one previous study on dietary patterns and dementia showing the beneficial effect of the Mediterranean diet [7] and of a dietary pattern low in AD-related nutrients [6], and our results are in accordance with these findings. Our study is the first to show that a healthy diet as early as at midlife is important 
Table 3. Association between healthy diet and dementia/AD among the CAIDE participants

\begin{tabular}{|c|c|c|c|}
\hline Healthy diet & $\begin{array}{l}\text { Model } 1 \\
\text { OR (95\% CI) }\end{array}$ & $\begin{array}{l}\text { Model } 2 \\
\text { OR }(95 \% \text { CI })\end{array}$ & $\begin{array}{l}\text { Model } 3 \\
\text { OR }(95 \% \text { CI })\end{array}$ \\
\hline \multicolumn{4}{|l|}{ Dementia } \\
\hline Low adherence ( $0-8$ points) & 1 (ref.) & 1 & 1 \\
\hline High adherence ( $>8$ points) & $0.14(0.02-0.80)$ & $0.10(0.01-0.71)$ & $0.12(0.02-0.85)$ \\
\hline \multicolumn{4}{|l|}{$A D$} \\
\hline Low adherence ( $0-8$ points) & 1 (ref.) & 1 & 1 \\
\hline High adherence ( $>8$ points) & $0.10(0.01-0.94)$ & $0.08(0.01-0.81)$ & $0.08(0.01-0.89)$ \\
\hline
\end{tabular}

Model 1 adjusted for age, sex, education, follow-up time, community of residence, and the APOE $\varepsilon 4$ carrier status; model 2 adjusted additionally for midlife SBP, serum total cholesterol, BMI, and the presence of late-life myocardial infarction/stroke/diabetes mellitus; model 3 adjusted additionally for midlife leisure-time physical activity and smoking.

for the prevention of dementia and $\mathrm{AD}$ in the elderly. Furthermore, our study extends the findings to more comprehensive dietary patterns than those captured by the Mediterranean-diet index only.

Our CAIDE healthy-diet index differs from the methods used in previous studies in that we were not able to take into account the total energy intake when calculating the index, and many of the variables were frequency based. On the other hand, our approach gives very practical information on the foods included, making it simple for a person to calculate his or her adherence to the healthy diet. In the calculation of the index, the median values were used as cutoffs, and general dietary recommendations were used to define what was healthy and what was unhealthy.

\section{Possible Mechanisms}

It is still unclear how a healthy diet exerts its effect on dementia. Its effect could be due to the specific characteristics of single beneficial nutrients and/or their combination. Oxidative stress may contribute to the neuronal damage in $\mathrm{AD}$, and reduced oxidative stress related to a healthy diet could explain the results [18]. Folate deficiency in diet can lead to high homocysteine levels, which has direct neurotoxic effects in cell lines and animal models [19]. The combination of vitamins E and C [20] has been shown to promote neuronal survival in rat brains. Furthermore, unsaturated fatty acids may influence the pathogenesis of AD by modulating, for example, the composition and fluidity of neuronal membranes and preventing neuro-inflammation [21].

Partly, the effect could be mediated through a vascular mechanism. A Mediterranean/ healthy diet has also been associated with cardiovascular risk factors, including hypertension, dyslipidemia, diabetes, and obesity $[22,23]$. In our analyses, we took into account several vascular risk factors and diseases, but an independent effect of a healthy diet still remained. Additionally, dietary habits are related to other social and lifestyle-related factors [24], and thus the association might be due to such confounding effects. In our analyses, we adjusted for several possible confounding factors, and the results remained unchanged. However, there might still be some residual confounding of unmeasured variables.

The trials conducted to prevent $\mathrm{AD}$ that have been carried out to test single nutritional components, such as vitamin E or C supplements, have yielded disappointing results [25]. So far, trials with a more complete nutritional intervention have not been done. For other out- 
comes, such as cardiovascular disease and diabetes, also the trials on single nutrients have not been very successful, whereas trials with more comprehensive dietary interventions have shown positive effects $[26,27]$. It would be interesting to see if comprehensive dietary interventions would also prevent or postpone dementia in susceptible persons. One multidomain trial, the Finnish Geriatric Intervention Study to Prevent Cognitive Impairment and Disability (FINGER), also including dietary intervention, has recently been initiated, and the results will eventually shed new light on this issue.

\section{Strengths and Limitations of the Study}

There are several strengths in our study. First, we had a population-based design, high participation rates (both at baseline and even at the re-examination), and both women and men were represented, all of which factors increase the generalizability of our findings. Second, dietary information was collected with the previously validated food frequency questionnaire (the primary method of dietary assessment in epidemiologic studies) because it refers to a whole year and is easy to complete [28]. Third, the dietary information was collected already at midlife (on average 14 years before the diagnosis of dementia), and therefore it was not prone to bias caused by subclinical dementia.

Reliance on self-report for data of dietary habits may constitute a limitation, although we do not believe that this would have led to systematic errors in reporting dietary habits (i.e. the future dementia did not affect how dietary habits were reported). The diet categories were derived from the nutritional data available. We did not have complete quantitative information, or information on some of the potentially interesting dietary factors (e.g. total energy intake, fiber intake, or intake of various vitamins). Fatty acid intake was derived from spreads and milk only, which constituted approximately $50 \%$ of the total dietary fat intake in Finland at the time of the midlife examinations [29]. However, due to the fact that many nutrients and dietary behaviors were included in the index, we were able to categorize people into groups of high and low adherence to a recommended diet in our population. Whether our CAIDE healthy-diet index is a valid tool for assessing the risk of dementia in other populations has still to be evaluated. We cannot completely exclude the possibility of residual confounding due to measurement error in the assessment of confounding factors, or the potential role of some unmeasured factors. However, we adjusted our analyses for a large number of potential confounding factors, but our results still remained significant. Our sample was relatively small, which led to large CIs, and we were not able to conduct stratified analyses in a reliable way. The non-participants of the follow-up study were more often demented (diagnoses from patient records) than the participants, but there were no significant differences in adherence to a healthy diet at midlife between the groups. Therefore, it is unlikely that selective non-participation would have biased our results.

\section{Conclusion}

To conclude, our results suggest that a healthy diet at midlife may be associated with a decreased risk of dementia/AD later in life. These findings highlight the importance of dietary patterns (instead of single nutrients) and might open possibilities to more effectively prevent or delay the onset of dementia/AD. The CAIDE healthy-diet index might be used as a tool to distribute information on the importance of dietary patterns in connection with the occurrence of dementia. However, this finding needs to be confirmed, and the index could be improved by large cohort studies with more accurate dietary data. Identification of mechanisms of how dietary habits exert their protection against dementia/AD might help in the development of new therapies for these diseases. 


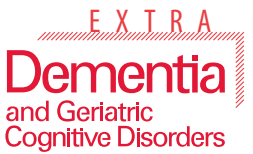

\section{Acknowledgments}

We thank the colleagues in the CAIDE study group for their cooperation in data collection and management; special thanks go to Alina Solomon, MD, for valuable comments on the manuscript. The study was supported by EVO grants of Kuopio University Hospital (5772720 and 5772709), the Academy of Finland (grants 103334, 206951, and 120676), an EU grant (QLK-2002-172) and an EU FP7 project LDD (211696), the Swedish Council for Working Life and Social Research, the Finnish Cultural Foundation, the Foundation of Juho Vainio, and the Yrjö Jahnsson Foundation. The funders had no role in the study design; in the collection, analysis, and interpretation of data; in the writing of the report, and in the decision to submit the article for publication. M.H.E., T.N., and M.K. had full access to all the data in the study and take responsibility for the integrity of the data and the accuracy of the data analysis.

\section{Disclosure Statement}

M.H.E., T.N., and J.T. have nothing to disclose. H.S. has served in the scientific advisory board for ACI. She has received royalties from publishing and being an editor and writer for a book on memory disorders in Finland, published by Duodecim. M.K. received honoraria for serving on the scientific advisory board of Elan and Pfizer, and serves as a speaker on scientific meetings organized by Janssen, Novartis, and Pfizer.

\section{References}

1 Laitinen MH, Ngandu T, Rovio S, Helkala EL, Uusitalo U, Viitanen M, Nissinen A, Tuomilehto J, Soininen H, Kivipelto M: Fat intake at midlife and risk of dementia and Alzheimer's disease: a population-based study. Dement Geriatr Cogn Disord 2006;22:99-107.

2 Gillette Guyonnet S, Abellan Van Kan G, Andrieu S, Barberger Gateau P, Berr C, Bonnefoy M, Dartigues JF, de Groot L, Ferry M, Galan P, Hercberg S, Jeandel C, Morris MC, Nourhashemi F, Payette H, Poulain JP, Portet F, Roussel AM, Ritz P, Rolland Y, Vellas B: IANA task force on nutrition and cognitive decline with aging. J Nutr Health Aging 2007;11:132-152.

3 Eskelinen MH, Ngandu T, Tuomilehto J, Soininen H, Kivipelto M: Midlife coffee and tea drinking and the risk of late-life dementia: a population-based CAIDE study. J Alzheimers Dis 2009;16:85-91.

4 Peters R, Peters J, Warner J, Beckett N, Bulpitt C: Alcohol, dementia and cognitive decline in the elderly: a systematic review. Age Ageing 2008;37:505-512.

5 Sofi F, Cesari F, Abbate R, Gensini GF, Casini A: Adherence to Mediterranean diet and health status: meta-analysis. BMJ 2008;337:a1344.

$6 \mathrm{Gu}$ Y, Nieves JW, Stern Y, Luchsinger JA, Scarmeas N: Food combination and Alzheimer disease risk: a protective diet. Arch Neurol 2010;67:699-706.

7 Scarmeas N, Stern Y, Tang MX, Mayeux R, Luchsinger JA: Mediterranean diet and risk for Alzheimer's disease. Ann Neurol 2006;59:912-921.

8 Scarmeas N, Luchsinger JA, Mayeux R, Stern Y: Mediterranean diet and Alzheimer disease mortality. Neurology 2007;69:1084-1093.

9 Feart C, Samieri C, Rondeau V, Amieva H, Portet F, Dartigues JF, Scarmeas N, Barberger-Gateau P: Adherence to a Mediterranean diet, cognitive decline, and risk of dementia. JAMA 2009;302:638648.

10 Vartiainen E, Puska P, Jousilahti P, Korhonen HJ, Tuomilehto J, Nissinen A: Twenty-year trends in coronary risk factors in North Karelia and in other areas of Finland. Int J Epidemiol 1994;23:495-504.

11 Kivipelto M, Helkala EL, Hanninen T, Laakso MP, Hallikainen M, Alhainen K, Soininen H, Tuomilehto J, Nissinen A: Midlife vascular risk factors and late-life mild cognitive impairment: a population-based study. Neurology 2001;56:1683-1689. 
12 The World Health Organization MONICA Project (monitoring trends and determinants in cardiovascular disease): a major international collaboration. WHO MONICA Project Principal Investigators. J Clin Epidemiol 1988;41:105-114.

13 Tsukamoto K, Watanabe T, Matsushima T, Kinoshita M, Kato H, Hashimoto Y, Kurokawa K, Teramoto T: Determination by PCR-RFLP of apo E genotype in a Japanese population. J Lab Clin Med 1993;121:598-602.

14 Folstein MF, Folstein SE, McHugh PR: 'Mini-mental state'. A practical method for grading the cognitive state of patients for the clinician. J Psychiatr Res 1975;12:189-198.

15 McKhann G, Drachman D, Folstein M, Katzman R, Price D, Stadlan EM: Clinical diagnosis of Alzheimer's disease: report of the NINCDS-ADRDA Work Group under the auspices of Department of Health and Human Services Task Force on Alzheimer's Disease. Neurology 1984;34:939-944.

16 Hachinski VC, Iliff LD, Zilhka E, Du Boulay GH, McAllister VL, Marshall J, Russell RW, Symon L: Cerebral blood flow in dementia. Arch Neurol 1975;32:632-637.

17 Trichopoulou A, Costacou T, Bamia C, Trichopoulos D: Adherence to a Mediterranean diet and survival in a Greek population. N Engl J Med 2003;348:2599-2608.

18 Steele M, Stuchbury G, Munch G: The molecular basis of the prevention of Alzheimer's disease through healthy nutrition. Exp Gerontol 2007;42:28-36.

19 Morris MS: Homocysteine and Alzheimer's disease. Lancet Neurol 2003;2:425-428.

20 Sato K, Saito H, Katsuki H: Synergism of tocopherol and ascorbate on the survival of cultured brain neurones. Neuroreport 1993;4:1179-1182.

21 Das UN: Folic acid and polyunsaturated fatty acids improve cognitive function and prevent depression, dementia, and Alzheimer's disease - but how and why? Prostaglandins Leukot Essent Fatty Acids 2008;78:11-19.

22 Franco OH, Bonneux L, de Laet C, Peeters A, Steyerberg EW, Mackenbach JP: The polymeal: a more natural, safer, and probably tastier (than the polypill) strategy to reduce cardiovascular disease by more than 75\%. BMJ 2004;329:1447-1450.

23 Sanchez-Tainta A, Estruch R, Bullo M, Corella D, Gomez-Gracia E, Fiol M, Algorta J, Covas MI, Lapetra J, Zazpe I, Ruiz-Gutierrez V, Ros E, Martinez-Gonzalez MA: Adherence to a Mediterraneantype diet and reduced prevalence of clustered cardiovascular risk factors in a cohort of 3,204 highrisk patients. Eur J Cardiovasc Prev Rehabil 2008;15:589-593.

24 Ambrosini GL, Oddy WH, Robinson M, O’Sullivan TA, Hands BP, de Klerk NH, Silburn SR, Zubrick SR, Kendall GE, Stanley FJ, Beilin LJ: Adolescent dietary patterns are associated with lifestyle and family psycho-social factors. Public Health Nutr 2009;12:1807-1815.

25 Luchsinger JA, Noble JM, Scarmeas N: Diet and Alzheimer's disease. Curr Neurol Neurosci Rep 2007; 7:366-372.

26 Lindstrom J, Peltonen M, Eriksson JG, Aunola S, Hamalainen H, Ilanne-Parikka P, Keinanen-Kiukaanniemi S, Uusitupa M, Tuomilehto J: Determinants for the effectiveness of lifestyle intervention in the Finnish diabetes prevention study. Diabetes Care 2008;31:857-862.

27 de Lorgeril M, Salen P, Martin JL, Monjaud I, Delaye J, Mamelle N: Mediterranean diet, traditional risk factors, and the rate of cardiovascular complications after myocardial infarction: final report of the Lyon Diet Heart Study. Circulation 1999;99:779-785.

28 Willett WC: Future directions in the development of food-frequency questionnaires. Am J Clin Nutr 1994;59:171S-174S.

29 Pietinen P, Uusitalo U, Vartiainen E, Tuomilehto J: Dietary survey of the FINMONICA project in 1982. Acta Med Scand Suppl 1988;728:169-177. 